ARTIGOS

ESPAÇO, ECONOMIA E POPULAÇÃO

\title{
AMÉRICA LATINA EM PERSPECTIVA: O PENSAMENTO CEPALINO E DECOLONIAL
}

\author{
Antônio Carlos Mazzetti* \\ Josiane Carine Wedig* \\ Miguel Angelo Perondi* \\ Marlize Rubin-Oliveira* \\ *Universidade Tecnológica Federal do Paraná, Programa de Pós-graduação em Desenvolvimento Regional, \\ Pato Branco, PR, Brasil
}

\begin{abstract}
Resumo
A América Latina, como lugar geográfico e epistêmico de características múltiplas, tem produzido tensionamentos à modernidade/colonialidade. A partir desse lugar, este ensaio tem por objetivo compreender as relações existentes entre a Comissão Econômica para a América Latina e Caribe (Cepal) e a perspectiva decolonial. Duas abordagens originadas na América Latina que têm como foco questões sociais, políticas, econômicas e ambientais. Para tanto, o caminho percorrido busca, por meio de um olhar sócio-histórico, compreender tais perspectivas com base em seus principais intelectuais, contextos e propostas. Por fim, conclui-se que se trata de perspectivas que, apesar dos caminhos diversos e distintos, têm objetivos que se entrecruzam e dialogam. Compreender aproximações e relações entre elas possibilitou destacar aspectos importantes na busca por alternativas à racionalidade hegemônica de exclusões e dependências impostas e perpetuadas desde a colonização.
\end{abstract}

Palavras-chave

América Latina; Desenvolvimento; Cepal; Perspectiva Decolonial; Centro $x$ Periferia. 


\author{
ARTICLES \\ SPACE, ECONOMY AND POPULATION
}

\title{
LATIN AMERICA IN PERSPECTIVE: ECLAC THINKING AND DECOLONIAL APPROACH
}

\author{
Antônio Carlos Mazzetti \\ Josiane Carine Wedig* \\ Miguel Angelo Perondit \\ Marlize Rubin-Oliveira* \\ *Universidade Tecnológica Federal do Paraná, Programa de Pós-graduação em Desenvolvimento Regional, \\ Pato Branco, PR, Brazil
}

\begin{abstract}
Latin America as a geographic and epistemic place with multiple characteristics has produced tensions towards modernity/coloniality. From this, the essay aims to understand the relationship between the Economic Commission for Latin America and the Caribbean (ECLAC) and the decolonial perspective. Two approaches originating in Latin America that focus on social, political, economic, and environmental issues. Therefore, the path taken seeks, from a socio-historical perspective, to understand these perspectives from their main intellectuals, contexts and proposals. Finally, it is concluded that these are perspectives of thought that, despite the diverse and distinct paths, have objectives that intertwine and dialogue. Understanding approaches and relationships made it possible to highlight important aspects in the search for alternatives to the hegemonic rationality of exclusions and dependencies imposed and perpetuated since colonization.
\end{abstract}

Keywords

Latin America; Development; ECLAC; Approach Decolonial; Center x Periphery. 


\title{
AMÉRICA LATINA EM PERSPECTIVA: O PENSAMENTO CEPALINO E DECOLONIAL
}

\author{
Antônio Carlos Mazzetti \\ Josiane Carine Wedig \\ Miguel Angelo Perondi \\ Marlize Rubin-Oliveira
}

Introdução

A América Latina, com base em suas características múltiplas, é tomada neste ensaio como um lugar geográfico e epistêmico. O continente, nomeado América em decorrência do processo de encobrimento do "outro" (DUSSEL, 1993), foi submetido à exploração de suas terras e gentes, lançado à condição de subalternidade. Com a implantação do colonialismo violento, racista e sexista, a Europa se posicionou como centro do que viria a ser o novo sistema-mundo colonial moderno (WALLERSTEIN, 1998; QUIJANO, 2005), estabelecendo uma relação de centro e periferia que segue operante mesmo após a (in)dependência política dos países colonizados.

A colonialidade do poder, do saber e do ser, que estabeleceu a classificação e a hierarquização dos povos e de seus saberes, segue exercendo controle mediante o domínio da ciência, da tecnologia, da economia e da globalização. As questões sociais, econômicas, ambientais e políticas latino-americanas permanecem renegadas pelo poder hegemônico (im)posto, reproduzindo a relação de poder do período colonial. A história subsequente nos mostra o desenvolvimento da América Latina envolto em dependências, crises políticas e democráticas e tensões entre a racionalidade eurocêntrica e resistências locais.

A questão do desenvolvimento ganha visibilidade após a Segunda Guerra Mundial, quando a tripartição em Primeiro, Segundo e Terceiro Mundos impôs uma classificação e uma hierarquização entre nações, especialmente no que concerne ao desenvolvimento econômico. Nesse contexto, uma perspectiva de análise 
se consolidou - a teoria da modernização -, em que os países subdesenvolvidos, do chamado Terceiro Mundo, deveriam rumar na direção da industrialização e da urbanização (LITTLE, 2002). A ideia de desenvolvimento se alicerçou na crença de progredir indefinidamente, com a indústria como a principal mola propulsora (DIEGUES, 1992).

A partir da década de 1950, foi retomado o interesse por questões de economia regional, embasadas em teorias de inspiração marshalliana e keynesiana, em função dos novos padrões de produção e dos movimentos de integração regional incentivados pelas relações econômicas do pós-guerra (CAVALCANTE, 2008). No contexto latino-americano, a discussão sobre o desenvolvimento passou a ser feita pela Comissão Econômica para a América Latina e o Caribe (Cepal), criada em 1948, como um braço da Organização das Nações Unidas (ONU), com foco no desenvolvimento econômico da região. A Cepal defende o multilateralismo e a governança global para a tomada de decisões e, atualmente, tem uma agenda de igualdade para o desenvolvimento sustentável e tecnológico da matriz produtiva latino-americana. Sua aposta recai no reconhecimento de uma mudança estrutural progressiva, com destaque para a questão ambiental e para a educação (BÁRCENA, 2018).

Em uma construção crítica ao desenvolvimento, a perspectiva decolonial, que se constitui com mais força a partir do final do século XX e início do século XXI, realiza uma análise histórico-social centrada nas consequências do colonialismo para a América Latina, cujos efeitos são visíveis até a atualidade. Essa perspectiva considera a necessidade de descolonização, respeitando o pensamento do "outro" não ocidentalizado (GROSFOGUEL, 2008).

As duas correntes originadas na América Latina têm como foco a análise de questões sociais, políticas, econômicas e ambientais. Assim, o objetivo deste ensaio é compreender as relações entre elas, com vistas a percorrer, valendo-nos de um olhar sócio-histórico, o caminho trilhado por essas perspectivas, considerando seus principais intelectuais, contextos e propostas.

Na primeira seção deste ensaio, apresenta-se o pensamento cepalino por meio das principais propostas para o desenvolvimento da América Latina, pautadas na industrialização e nos avanços técnico-científicos. Tomam-se como ponto de partida os escritos de Celso Furtado e Raúl Prebish. Na segunda seção, a perspectiva decolonial é discutida com base na caracterização do colonialismo e da colonialidade do poder, do saber e do ser, considerando a emergência do grupo de pesquisa Modernidade/Colonialidade, que propôs a análise de alguns dos principais aspectos da realidade social, política, econômica, cultural e ambiental da América Latina. Na terceira seção são identificadas as relações existentes entre as duas perspectivas de pensamento. E, por fim, tecem-se as considerações finais, em 
que indicamos alguns questionamentos que apontam possibilidades de pesquisas futuras sobre o tema.

\section{A Cepal e o desenvolvimento na América Latina}

A Cepal é uma das cinco comissões regionais da ONU, com sede na cidade de Santiago, no Chile. Criada com o objetivo de contribuir com o desenvolvimento econômico da América Latina, ela reforça relações entre seus países-membros e destes com outras nações do mundo.

Alguns dos principais autores do pensamento cepalino são Raúl Prebisch, Aníbal Pinto, Celso Furtado, Aldo Ferrer, Fernando Henrique Cardoso e Osvaldo Sunkel (BIELSCHOWSKY, 1998; ESCOBAR, 2007). A produção acadêmica dos autores da Cepal sofreu mudanças ao longo do tempo, associadas às transformações vivenciadas no contexto da América Latina. O conceito de desenvolvimento linear e baseado num modelo ocidental vai se tornando mais complexo e é questionado no tocante à necessidade de incorporação de aspectos sociais locais, fugindo da lógica de modelo único (WOLFE, 1976; GRACIARENA, 1976).

Conforme o sítio da Cepal, ao longo de sua história essa comissão tem contribuído com o desenvolvimento latino-americano ao promover transformações da realidade econômica, social e política regional e mundial. Sua história é marcada por cinco etapas: i) da origem à década de 1950, seu foco de atuação foi na industrialização para substituir/reduzir importações; ii) nos anos 1960, propôs reformas para a consecução desse intento; iii) na década de 1970, passou a reorientar o desenvolvimento para a homogeneização social e a diversificação da exportação; iv) na década de 1980, realizou ajustes no crescimento econômico com vistas a reduzir o endividamento externo; v) nos anos 1990, preconizou a transformação produtiva com equidade (CEPAL, 2019). Daquele período até 2008, a economia da região viveu um período positivo, mas a crise que surgiu então levou à necessidade de rediscutir a realidade regional, quando a Cepal propôs uma agenda centrada na igualdade e no desenvolvimento sustentável (BÁRCENA, 2018).

Países de desenvolvimento tardio - assim foram chamados os países da América Latina em relação aos desenvolvidos. Sobre esse aspecto, Celso Furtado (1977) - que integrou a Cepal desde sua criação, em 1948 - fez uma análise dos fatores que interferem no desenvolvimento no que se refere às formas de acumulação de capital e à emergência da economia industrial moderna. Para ele, a apropriação e a utilização do excedente estão na base da organização social e das estruturas de poder, controladas por grupos estrangeiros, dos países centrais, com interesses contrários aos da coletividade daqueles periféricos, constituindo um obstáculo ao desenvolvimento destes. Nesse sentido, o desenvolvimento consiste em um 
processo de transformação que engloba o conjunto da sociedade e deve partir da apreensão da realidade social e econômica.

A base de análise de Celso Furtado (1992) está fortemente ligada ao Estado como fomentador do desenvolvimento econômico ancorado no mercado interno, por intermédio da industrialização, da urbanização e da tecnologia moderna. Ele analisou a estrutura mundial de poder, com foco nas questões macroeconômicas, a fim de observar como se estabeleceu a economia primário-exportadora herdada da era colonial, efetivada pela exploração de recursos, no Brasil e em outros países periféricos. Para o autor, esses países buscam o caminho da industrialização, mas, por falta de autofinanciamento e de demanda interna, acabam dependentes do acesso marginal ao mercado internacional, dominado por empresas transnacionais de países centrais, que ditam os preços praticados e controlam os espaços econômicos nas periferias.

Além da industrialização voltada ao mercado interno, Celso Furtado (1992) defende que países com sistemas econômicos de grandes dimensões territoriais precisam contar com vontade política apoiada em um projeto que leve em conta suas raízes históricas. O principal desafio desses países é preservar sua identidade cultural, assim como a unidade política, num mundo dominado por grupos transnacionais que controlam a tecnologia, a informação e o capital financeiro. Segundo o autor, nos países centrais se concentram a produção industrial, o controle de patentes e das atividades intelectuais, além das atividades criativas, inovadoras e outras que atuam como instrumentos de poder, contribuindo para ampliar as desigualdades entre países desenvolvidos e subdesenvolvidos. Além disso, Furtado (1992, p. 58) demonstra que:

A estrutura internacional de poder evoluiu para assumir a forma de grandes blocos de nações-sedes de empresas transnacionais que dispõem de rico acervo de conhecimentos além de pessoal capacitado. O intercâmbio internacional de serviços, particularmente os financeiros e tecnológicos, cresce em detrimento do de bens tradicionais. Na dinâmica desse sistema, prevalecem as forças tendentes a reproduzir a atual clivagem desenvolvimento/subdesenvolvimento. Para escapar a esse sistema de forças articuladas planetariamente, é necessário que se conjugue vontade política fundada em amplo consenso social com condições objetivas que poucos países do Terceiro Mundo reúnem atualmente.

Assim, as análises e proposições desse autor, voltadas principalmente para o desenvolvimento econômico tardio da América Latina, contribuíram para um debate ainda pouco explorado naquele momento. Furtado insere no debate uma ideia de não linearidade ao desenvolvimento econômico. 
Outro autor fundamental do pensamento cepalino foi Raúl Prebisch (1962) - o segundo secretário executivo da Cepal, entre 1950 e 1963 -, que abordou a divisão internacional do trabalho, em que couberam à periferia do sistema econômico mundial a produção e o fornecimento de alimentos e matérias-primas para a indústria dos países centrais. $\mathrm{O}$ autor observou a acentuada diferença no padrão de vida das massas dos países centrais em relação aos periféricos, apontando que a industrialização era o meio para captar parte do fruto do progresso técnico e elevar progressivamente o padrão de vida das periferias. A ênfase de seu pensamento estava direcionada ao desenvolvimento econômico da América Latina, razão pela qual ele defendia a necessidade de considerar as especificidades da região, afastando-se de uma análise universal baseada nas experiências das economias centrais. Não obstante, Raúl Prebisch e os economistas da Cepal propuseram formas de capitalização dos países periféricos mediante o progresso técnico, que já havia ocorrido nos países centrais.

Posteriormente, Prebisch $(1963 ; 1978)$ reconheceria a dificuldade para superar falhas estruturais que criavam obstáculos ao progresso técnico e ao desenvolvimento econômico e social latino-americano. Para o autor, era imprescindível uma nova ordem na econômica dos países periféricos que superasse a estrutura social assentada em privilégios e na má distribuição de riqueza, inibidora do surgimento de elementos dinâmicos da sociedade, do estímulo à atividade econômica e de iniciativas capazes de mudar aquela realidade.

De acordo com Renato Colistete (2001), no núcleo da teoria cepalina do subdesenvolvimento na América Latina há duas proposições, uma de caráter estrutural doméstico e outra de aspecto internacional: i) as economias dos países da região estão estruturadas com foco no setor primário-exportador, construído historicamente desde o período colonial, em que se verifica a ausência de uma indústria dinâmica; ii) pouco investimento/preocupação com o progresso técnico e o aumento de produtividade, o que favorece os países centrais nas relações de importação de produtos primários em contrapartida à exportação de manufaturados.

Com relação à primeira proposição, foi recomendado, no início dos anos 1960, que "a industrialização teria de incorporar setores de bens de produção mais complexos e capazes de gerar e difundir progresso técnico por toda a estrutura industrial” (COLISTETE, 2001, p. 25). Por sua vez, a segunda proposição gerou questionamentos, já que a produção primário-exportadora poderia implementar tecnologias com vistas ao aumento de produtividade e à elevação de renda, a exemplo do que aconteceu com Noruega, Dinamarca e Finlândia. Maria da Conceição Tavares (2019a) considerou simplista a proposta cepalina de "substituição de importações" - que se referia à transformação do modelo primário-exportador para um modelo 
industrial, voltado ao mercado interno -, visto que seria preciso levar em conta o fato de que as economias centrais tinham uma indústria forte de manufaturas baseada em investimento autônomo e tecnologia, o que faltava aos países periféricos. Essa distinção estava no cerne da problemática do crescimento na América Latina, diretamente vinculado ao quadro de divisão internacional do trabalho, imposto e liderado pelos países centrais.

A autora ainda evidencia que as crises mundiais da primeira metade do século XX pressionaram e estimularam a atividade industrial interna das economias periféricas, porém a produção final necessitava de insumos básicos e produtos intermediários, nem sempre disponíveis ou produzidos no país; sua importação, entretanto, levava a uma substituição de importações mais aparente do que efetiva. Internamente, era preciso lidar com a estrutura do mercado e a demanda, com a defasagem tecnológica e com os problemas de recursos produtivos, com a oferta de recursos naturais abundantes, mas deficiência de mão de obra qualificada e de capital (TAVARES, 2019a).

Contudo, as teorias cepalinas que partiram da realidade econômica latinoamericana e propuseram formulações e ajustes nas políticas a serem adotadas pelos países - baseadas na "industrialização apoiada pela ação do Estado" como "forma básica de superação do subdesenvolvimento latino-americano" - foram cruciais, tanto para seu êxito como para os questionamentos gerados. Essas proposições foram amplamente aceitas por policy makers, empresários e industriais latinoamericanos, bem como no meio acadêmico, inclusive no Brasil, uma vez que "o que a teoria cepalina perdeu em precisão e consistência foi possivelmente mais do que compensado pelos ganhos em termos de simplicidade e de apelo entre policy makers e público em geral” (COLISTETE, 2001, p. 21, 26).

De acordo com a descrição feita pelo documento da ONU (2019) sobre a Cepal, sua presença no Brasil ocorreu em decorrência de um acordo de colaboração com o Banco Nacional de Desenvolvimento Econômico e Social (BNDES), no ano de 1952, resultante da criação de um grupo misto de estudos, sediado no Rio de Janeiro. $\mathrm{Na}$ década de 1960, com a desvinculação do BNDES, estabeleceu-se, na mesma cidade, o escritório regional da Cepal, como Instituto Latino-Americano de Planejamento Econômico e Social (Ilpes). O escritório foi transferido para Brasília em 1978, por conta de um acordo firmado entre o governo brasileiro e o Instituto de Pesquisa Econômica Aplicada (Ipea).

Considerando esses aspectos, Renato Colistete (2001) aponta que a herança da Cepal no pensamento econômico do Brasil pode ser descrita em quatro dimensões relacionadas: i) a ênfase nas estruturas econômicas; ii) o papel reduzido dos atores sociais; iii) a predominância de uma perspectiva macroeconômica; e iv) o desenvolvimento de uma análise dos processos históricos da periferia e do 
subdesenvolvimento, concentrando-se na caracterização das estruturas. É importante destacar que a primeira dessas dimensões acaba gerando como consequências as outras três. E essa herança tem determinado os "temas e aspectos da realidade econômica que são privilegiados ou deixados de lado em suas análises” (COLISTETE, 2001, p. 32).

A atuação da Cepal ampliou-se significativamente nos últimos anos, abarcando áreas ligadas ao desenvolvimento econômico, social, sustentável, produtivo e empresarial, assim como a aspectos relacionados a assentamentos humanos, recursos naturais, estatísticas, população e desenvolvimento, comércio internacional e integração, assuntos de gênero, planejamento para o desenvolvimento. Além disso, atua e apoia a implementação da Agenda 2030 e dos Objetivos de Desenvolvimento Sustentável (ODS) da ONU junto aos países-membros (ONU, 2019). Vale destacar que tanto a Agenda como os ODS fazem parte de ações que visam combater a pobreza, proteger o meio ambiente e o clima e garantir paz e prosperidade às pessoas, em todos os lugares.

Octavio Rodríguez (2009, p. 44) destaca que a discussão sobre desenvolvimento na Cepal sofreu mudanças, pois “certas tendências básicas do desenvolvimento das economias periféricas encontram sua explicação no modo como o aparelho produtivo vai se transformando". O autor discute a história da Comissão, desde as ideias inicias de Prebisch - assentadas na bipolaridade centro e periferia - até a renovação da agenda de desenvolvimento entre a década de 1980 e o início do século XXI, no contexto da globalização e da concepção do desenvolvimento como processo integral, contemplando os âmbitos econômico, social, político, cultural e ambiental.

Alicia Bárcena (2018), atual secretária executiva da Cepal - única mulher a ocupar o posto até hoje -, em seu discurso na comemoração dos setenta anos da Comissão, em janeiro de 2018, fez um breve resgate histórico da organização, apontando os novos desafios apresentados pela globalização. Ela apontou a relevância de um período positivo na economia da região, dos anos de 1990 até a crise de 2008, que atingiu vários países e trouxe a necessidade de ampliar o debate econômico, social e ambiental. A Cepal propôs, em 2009, uma agenda com foco na igualdade, no desenvolvimento sustentável e nas mudanças tecnológicas da matriz produtiva.

Essas proposições levam em consideração as mudanças geopolíticas recentes, como a ascensão da China, a tendência ao protecionismo econômico dos Estados Unidos e da Europa, a migração Sul-Norte, a revolução tecnológica, o crescimento das redes de negócios virtuais, as mudanças nas hierarquias de poder e o impacto desse novo contexto nos Estados e sociedades da América Latina. Especificamente em relação à revolução tecnológica, afirma-se que em geral ela vem de fora e não é produzida na região. Segundo Bárcena (2018, p. 62): 
A ruptura digital não vai esperar por nós. Chegar tarde às revoluções industriais dos séculos XIX e XX nos custou um grande atraso do qual não saímos. Não podemos repetir esse fracasso na revolução digital. O instrumento que a Cepal propõe e tem ampla aceitação na região é avançar para um mercado digital regional que permita aproveitar as economias de escala e de rede para atingir um mercado potencial de 600 milhões de pessoas, das quais mais da metade já está conectada (tradução nossa).

Adicionalmente, Alicia Bárcena (2018) aponta para a transformação de um contexto de industrialização massiva em uma economia digital e da informação, com os países da América Latina apresentando capacidade de produzir essas tecnologias para seus mercados internos. Para a autora, é preciso aprender com o passado e reconhecer a mudança estrutural progressiva levando em consideração as questões ambientais. Ela aposta na educação como forma de reduzir desigualdades e de gerar e ampliar capacidades e oportunidades. E salienta, por fim, que, como as questões são globais, não se pode pensar em soluções uni ou bilaterais; o multilateralismo e a governança global se configuram como pilares centrais e fundamentais para o bem-estar mundial.

Para Renato Colistete (2001), a teoria cepalina perdeu força ao longo dos anos, embora tenha deixado marcas que persistem no pensamento econômico atual da América Latina, a exemplo da ênfase no investimento, pelos Estados nacionais, nas estruturas. De acordo com Maria da Conceição Tavares (2019b), o processo substitutivo se esgotou e deu lugar a uma transição para um novo esquema de desenvolvimento capitalista, que pode se apresentar com características dinâmicas, mas também reforçar traços de exclusão social, concentração espacial e atraso nos níveis de produtividade de certos subsetores.

Com ênfase maior na análise do processo sócio-histórico e menos nos aspectos econômicos, a perspectiva decolonial emerge na década de 1990 na análise dos processos de subalternização dos povos da América Latina pelas estruturas da modernidade colonial/eurocentrada, ainda operante pela colonialidade do poder, do saber e do ser, tema da próxima seção.

\section{Perspectiva decolonial e o (pós-)desenvolvimento}

O ponto de partida da perspectiva decolonial é a análise do processo do colonialismo, que se inicia em 1492, com o "descobrimento” da América (DUSSEL, 1993). Estabeleceu-se com isso o "sistema-mundo colonial moderno", que dividiu o mundo entre centro e periferia (WALLERSTEIN, 2001; QUIJANO, 2005), e a América Latina foi transformada na primeira periferia global, da qual a Europa era/é o centro. 
Conforme Aníbal Quijano (2005), esse sistema de dominação teve como elemento fundador a ideia de raça, que inaugura uma classificação da população mundial, atribuindo a uma suposta diferença de estrutura biológica a condição de inferioridade de uns em relação a outros, respectivamente não europeus e europeus. A América passa a ser um território explorado pelas forças coloniais, que causaram o genocídio dos povos indígenas e a escravização dos povos africanos - violentamente arrancados de seus territórios para realizar trabalho forçado nas plantations, cuja produção servia ao acúmulo de riqueza para a população branca europeia. $\mathrm{O}$ autor vê a globalização como a culminação desse processo de padronização de poder, no qual a América Latina está inserida como periférica no desenvolvimento do sistema-mundo colonial moderno, cujas estruturas se ampliam e aprofundam as desigualdades sociais (QUIJANO, 2014).

Com a (in)dependência dos países latino-americanos dos colonizadores europeus, nos séculos XIX e XX, não ocorreu uma descolonização real. De acordo com Ramón Grosfoguel (2008), originou-se no século XX o mito de um mundo pós-colonial, apesar da persistência da égide da mesma matriz de poder colonial, com os países submetidos às formas coloniais de dominação. "Com a descolonização jurídico-política saímos de um período de 'colonialismo global' para entrar num período de "colonialidade global”' (GROSFOGUEL, 2008, p. 126).

No período subsequente à Segunda Guerra Mundial, o debate pós-colonial passa a ser realizado especialmente nos continentes asiático e africano. Walter Mignolo (2017) afirma que as bases históricas desse pensamento se desenvolveram na Conferência de Bandung, na Indonésia, em 1955, onde se reuniram representantes de 29 países da Ásia e da África, em busca de um futuro que fugisse à dicotomia da racionalidade capitalista e/ou comunista, base da Guerra Fria. Além disso, em 1961, em Belgrado (Sérvia), ocorreu a Conferência dos Países Não Alinhados, na qual os países latino-americanos se juntaram ao movimento de contestação à colonialidade.

Também em 1961 foi publicada a obra Os condenados da terra, de Frantz Fanon, um exame das consequências da guerra de independência da Argélia, que, em uma luta anticolonial africana, buscou libertar-se das violências coloniais, da imposição da divisão de raças e da classificação do nativo posto como estrangeiro no próprio país. Fanon (1968) defendia a necessidade do despertar de uma nova humanidade, que, ao ressurgir e reagir, seria capaz de retomar o que é seu e expulsar o invasor. Essa obra é um dos marcos dos estudos decoloniais e pós-coloniais.

A ênfase do pensamento pós-colonial recaiu então sobre os movimentos de resistência e combate à exploração dos países do Terceiro Mundo pelo imperialismo e o neocolonialismo. Na década de 1970, essa perspectiva foi reforçada com o surgimento do Grupo de Estudos Subalternos no Sul asiático, que tem entre 
seus princípios o conceito de subalternidade e a necessidade de ouvir aqueles que não têm voz nos discursos e práticas coloniais, o que nem sempre significa autorizar intelectuais a falarem por eles. As contribuições desses intelectuais ganham mais evidência nos anos de 1980 em algumas universidades inglesas e estadunidenses. Conforme Luciana Ballestrin (2013, p. 91), a perspectiva póscolonial partiu da "diferença colonial e intercedeu pelo colonizado", constituindose em "um argumento comprometido com a superação das relações de colonização, colonialismo e colonialidade”.

Para a autora, o Grupo Latino-Americano de Estudos Subalternos inseriu a América Latina no debate pós-colonial, e foi em decorrência das tensões e das críticas a ele direcionadas que emergiu na região o pensamento decolonial, concretizado com a formação do Grupo Modernidade/Colonialidade (M/C), composto, em sua maioria, de intelectuais latino-americanos. Eles foram responsáveis por criar um "movimento epistemológico fundamental para a renovação crítica e utópica das Ciências Sociais na América Latina no século XXI: a radicalização do argumento pós-colonial no continente através da noção de 'giro decolonial”' (BALLESTRIN, 2013, p. 116).

Portanto, a perspectiva decolonial consolidou-se a partir dos anos 1990, quando começou a ser estudada e ampliada nas universidades latino-americanas. Alguns dos principais teóricos do pensamento decolonial são Enrique Dussel, Aníbal Quijano, Walter Mignolo, Arturo Escobar, Ramón Grosfoguel, María Lugones. Outros, como Immanuell Wallerstein, Boaventura de Sousa Santos e Catherine Walsh, inserem-se no âmbito dessa perspectiva por dialogarem com ela (BALLESTRIN, 2013).

Nos termos de Arturo Escobar (2003, p. 53), há um número significativo de fatores que compõem a genealogia do pensamento decolonial, dentre os quais se incluem a "teologia da libertação", a "filosofia da libertação e a ciência social autônoma", a "teoria da dependência", os "debates latino-americanos sobre a modernidade e a pós-modernidade", as "discussões sobre hibridez na antropologia, na comunicação e nos estudos culturais" e também o "grupo de estudos subalternos". Escobar revela ainda que o grupo $\mathrm{M} / \mathrm{C}$ foi inspirado por teorias críticas europeias e estadunidenses, pelos estudos subalternos sul-asiáticos, pelas teorias feministas das mulheres latinas, assim como pela teoria pós-colonial e a filosofia africana. Seu foco de análise principal é a realidade social, cultural e política latino-americana e o conhecimento dos subalternizados.

Walter Mignolo (2017, p. 16) destaca o pensamento fronteiriço como singularidade epistêmica do projeto decolonial, pois, para ele, "a epistemologia fronteiriça é a epistemologia do anthropos que não quer se submeter à humanitas, ainda que ao mesmo tempo não possa evitá-la”. A epistemologia fronteiriça conduz 
ao desprendimento das racionalidades políticas, econômicas e sociais eurocêntricas e nos lança em busca de formas de vida e modos de pensamento distintos. Nesse contexto, as categorias e classificações que inferiorizam as sociedades periféricas não passam de ficção criada pelos “colonializadores” para dominá-las - e o Terceiro Mundo seria uma invenção de quem se colocou acima dele.

Para Ramón Grosfoguel (2008, p. 117), há três aspectos fundamentais da perspectiva epistêmica decolonial: i) exige-se um cânone de pensamento mais amplo que o ocidental; ii) que não se baseie num universal abstrato, mas se volte a um mundo pluriversal, num diálogo crítico que envolva projetos políticos, éticos e epistêmicos; e, por fim, iii) que sejam levadas a sério as perspectivas, cosmologias e visões pensadas de forma crítica "a partir de corpos e lugares étnico-raciais/sexuais subalternizados” do Sul global.

Segundo Guilherme Radomsky (2011, p. 157), o grupo M/C é uma associação crítico-propositiva promissora, com a inspiração de fontes teóricas propriamente latino-americanas, “como as obras de José Carlos Mariátegui, Darcy Ribeiro e Paulo Freire”. As proposições analíticas dos autores desse grupo visam desconstruir as narrativas eurocêntricas ocidentalizadas sobre o progresso enquanto linearidade histórica, na tentativa de reconfigurar uma política epistêmica e dar visibilidade à colonialidade que continua a operar intensamente na perspectiva hegemônica de desenvolvimento.

Neste sentido, a perspectiva decolonial apresenta diversas possibilidades, como a transmodernidade e o bem viver. A primeira, proposta por Enrique Dussel (1995), visa transcender a modernidade eurocentrada, descolonizar as estruturas de poder global e estabelecer um diálogo intercultural entre Norte e Sul, como formas alternativas de vida. Já o conceito de bem viver parte de olhares de povos indígenas latino-americanos, apontando para um conjunto de ideias em reação ao conceito de desenvolvimento hegemônico e, ao mesmo tempo, se propõe como alternativa a este. Ele emerge das distintas cosmologias desses povos, em relação às dinâmicas sociais e ambientais, buscando descolonizar os saberes, libertando-se das racionalidades ocidentais impostas e respeitando a diversidade de culturas (GUDYNAS, 2011).

A perspectiva decolonial, ao sensibilizar-se com processos sócio-históricos da América Latina, insere no debate perspectivas subalternas e periféricas até então encobertas nas análises econômicas. Assim, quando tomamos a região como um lugar geográfico e epistêmico, é possível perceber relações entre o pensamento cepalino e decolonial, bem como identificar algumas ferramentas teóricas para a análise social, política e econômica da região. É sobre esses aspectos que foi construída a próxima seção. 


\section{Cepal e a perspectiva decolonial: relações possíveis}

Entre o pensamento decolonial e o cepalino observam-se diálogos constantes, em especial aqueles produzidos pelos autores decoloniais. Ao tempo em que representantes de ambas as perspectivas demonstram seu interesse comum pelo desenvolvimento da região, percebe-se que os autores da Cepal não se dedicaram a analisar intensamente as consequências do colonialismo e o modo como, com base nele, foi criado um padrão de acumulação na economia mundial, pautado na extração de produtos primários da América Latina, deixando empobrecidos os países de onde, por exemplo, o ouro fora extraído para se transformar em acúmulo de reservas de capital nos países centrais. Nesse sentido, a riqueza desses países não resulta apenas do progresso técnico e do desenvolvimento industrial - como a maior parte dos autores cepalinos aponta -, e sim da relação de genocídio e exploração do trabalho e dos recursos dos países periféricos, como será demonstrado pelos autores decoloniais.

Alguns dos principais conceitos mobilizados por ambas as perspectivas podem ser observados na Figura 1.

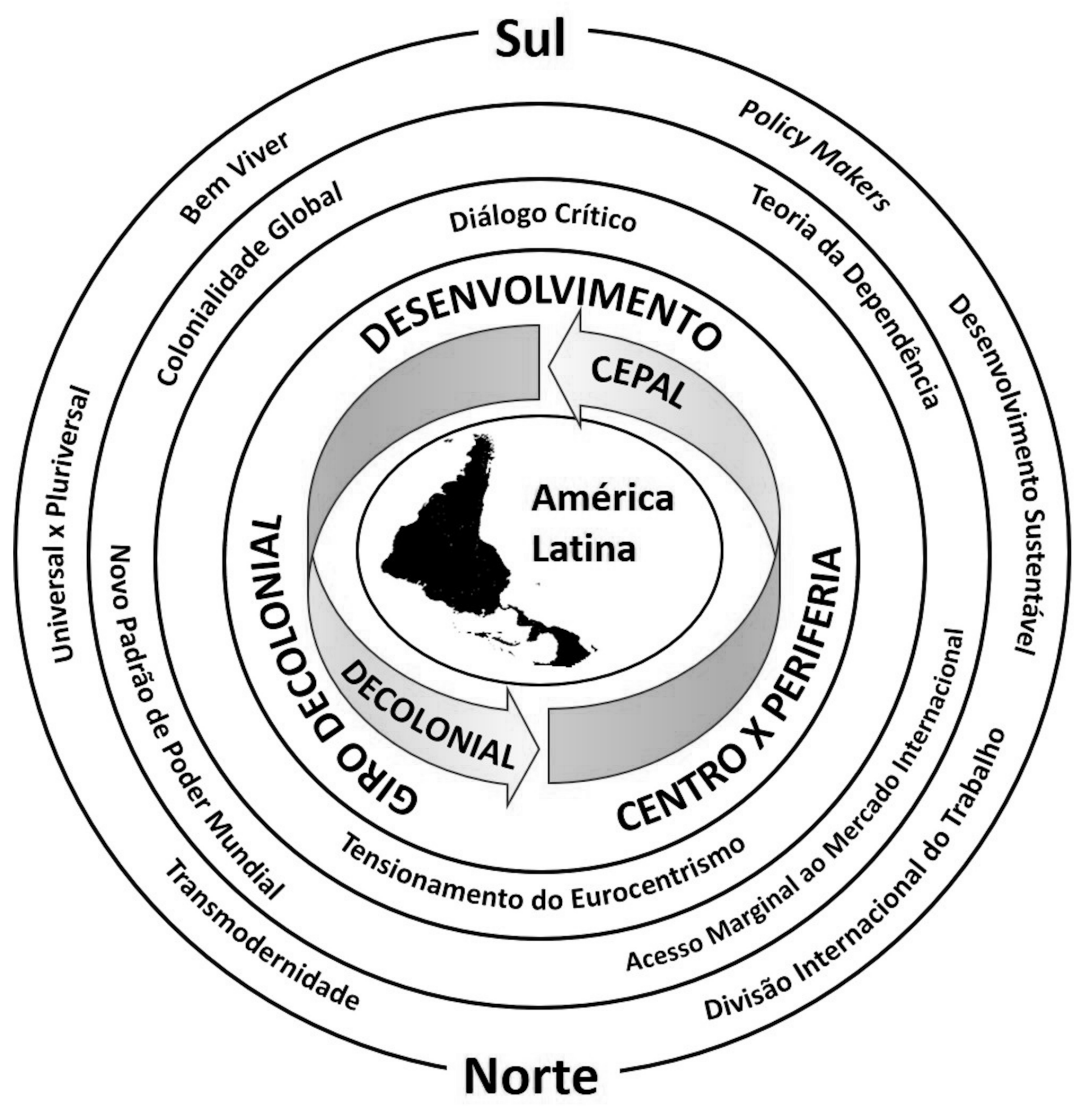

Figura 1. Cepal e perspectiva decolonial: relações possíveis.

Nota: Elaborada pelos autores. 
Alguns conceitos atravessam ambas as perspectivas analíticas sobre a América Latina, como é o caso da concepção de centro-periferia, que tem origem no pensamento da Cepal e que também sustenta o pensamento decolonial. O modelo de desenvolvimento econômico proposto pela Cepal aponta para a relação centro e periferia e para o modo como esta favorece os países centrais nas trocas comerciais de importação e exportação. O foco dessa análise está no período do século XX e indica a necessidade de expansão da industrialização das economias periféricas no marco de suas relações comerciais com os centros, transformando a estrutura produtiva periférica com o apoio da estratégia de substituição das importações por industrialização interna dos países periféricos (RODRÍGUEZ, 1986). Por sua vez, a relação centro e periferia na perspectiva decolonial é estabelecida com base no conceito de sistema-mundo moderno colonial, cuja conformação excludente e desigual se configura com o aporte de condições histórico-culturais, em que o europeu se autodefiniu como moderno e avançado, enquanto outros povos foram classificados como atrasados (QUIJANO, 2005; WALLERSTEIN, 2001). Estabelece-se assim, desde o colonialismo, uma pressuposição do caráter universal da experiência europeia, uma narrativa evolucionista, linear, em que a culminação de todos os povos do planeta seria seguir o modelo euro-norte-centrado (LANDER, 2005). Em face da discussão sobre o desenvolvimento produzida pela Cepal, Octavio Rodríguez (1986) destaca a ênfase no crescimento econômico de ampliação do setor industrial voltado ao mercado interno, com menor consideração das relações sociais referentes à classe trabalhadora e aos despossuídos.

Para Arturo Escobar (2005), a experiência de desenvolvimento significou para muitos o rompimento com o lugar, com os modelos culturais e os conhecimentos, problemática que tem sido enfrentada nos debates sobre o pós-desenvolvimento. $\mathrm{O}$ autor afirma, ainda, que os debates sobre o lugar e sua relação com a globalização são úteis e necessários porque os contrapõem ao domínio do espaço local por forças externas e abrem espaços para pensamentos outros, com o objetivo de repensar alternativas para a globalização, o capitalismo e a modernidade. 0 lugar é o "outro” da globalização e tais discussões viabilizam possibilidades de uma nova concepção de mundo e sua reconstrução como resultado das práticas e dos conhecimentos locais, rearticulando subjetividades e alteridades nas dimensões econômicas, culturais e ecológicas.

As críticas ao conceito de desenvolvimento hegemônico (euro-norte-centrado) também foram elaboradas pelos teóricos da dependência, pela teologia e filosofia da libertação (MIGNOLO, 2008, p. 295). Para Rodolfo Stavenhagen (1984), a teoria da dependência corresponderia ao reverso da teoria do imperialismo; embora ambas se refiram ao problema do capitalismo, a segunda o faz sob o ponto de vista 
dos países industrializados e a primeira, sob o ponto de vista do Terceiro Mundo. Para o autor, o "subdesenvolvimento não significava mais 'ser atrasado', mas sim 'ser dependente e explorado”' (STAVENHAGEN, 1984, p. 15-16). Com isso, identifica-se que a narrativa linear do progresso técnico, antes definida como a condição de atraso da América Latina, estava equivocada.

Nas décadas de 1960 e 1970, a teoria da dependência - elaborada por teóricos como Fernando Henrique Cardoso, Enzo Faletto, André Gunder Frank, Theotônio dos Santos e Aníbal Quijano - defendia a necessidade de uma análise específica para a América Latina, com loci de enunciação na região. Essa escola criticava a estratégia de industrialização em substituição à importação, o que acabou por promover a proliferação de multinacionais na região, agravando os problemas da balança de pagamentos e transformando a dependência industrial em dependência tecnológica (GROSFOGUEL, 2013).

Alguns intelectuais dialogaram diretamente com o pensamento cepalino e decolonial, como Aníbal Quijano, o autor que mais transita entre as duas abordagens e que viria a ser um dos principais membros do grupo $\mathrm{M} / \mathrm{C}$; antes, entre 1966 e 1971, ele atuou na Cepal como pesquisador do Programa de Investigações sobre Urbanização e Marginalidade, na Divisão de Assuntos Sociais. Sua obra se fundamenta na heterogeneidade de experiências intelectuais, políticas e estéticas da América Latina. A despeito da clara influência de Marx e de Mariátegui, Quijano navega por variados campos intelectuais e fornece um retrato de sua visão das relações regionais e globais.

Como participante da discussão de temas centrais da Cepal, da elaboração da teoria da dependência e da discussão sobre centro e periferia, Quijano contribuiu com a interpretação dessa relação, denunciando os favorecimentos mútuos entre os países centrais e as elites dos países latino-americanos, em detrimento dos interesses das populações subalternizadas (CLÍMACO, 2014). Aníbal Quijano (2014) analisou as consequências da colonialidade sobre os países colonizados, e, segundo seu ponto de vista, a classificação racial, como forma de dominação nascida no período colonial, persiste na atualidade, constituindo o eixo fundamental do padrão de poder mundial e perpetuando a colonialidade do poder.

Muitas outras questões, certamente, podem e devem ser discutidas nas imbricações Cepal e perspectiva decolonial - por exemplo, a contribuição de autores brasileiros. Nessa Comissão, Celso Furtado e Fernando Henrique Cardoso exerceram forte influência. O primeiro atuou na política brasileira como ministro de Estado nos governos de João Goulart (1962) e de José Sarney (1986-1988), além de ter ocupado outros postos de governo. Fernando Henrique Cardoso, sociólogo, um dos intelectuais associados à Escola da Dependência, teve sua obra intelectual ligada 
à análise da América Latina, além de ter sido eleito como presidente da República por duas gestões (entre 1995 e 2003).

Para a perspectiva decolonial, contribuíram, direta ou indiretamente, autores como Darcy Ribeiro e Paulo Freire, considerando o papel da educação no processo de emancipação da América Latina. O primeiro acreditava na universidade como instrumento de mudança na reescrita possível da história e no alinhamento desse pensamento com o movimento decolonial (RIBEIRO, 2014). Paulo Freire (2005), por sua vez, propunha a educação como instrumento para desconstruir o mito da estrutura opressora, pautada na liberdade na perspectiva do oprimido, com a desconstrução do mito do eurocentrismo e a criação de um novo lugar de fala, em favor de um ensino menos colonizado (FREIRE, 2005; PENNA, 2014). Esses dois autores, mesmo que não considerados diretamente decoloniais, são apontados como precursores importantes para a construção das bases do pensamento decolonial.

Como é possível observar, os diálogos entre as duas perspectivas, aqui em destaque, são movimentos de resistência e apresentam possibilidades concretas de construção de alternativas ao modelo moderno/colonial de desenvolvimento.

\section{Considerações finais}

Este artigo visou dar destaque a algumas relações entre o pensamento cepalino e decolonial, no que se refere, principalmente, à construção de alternativas ao modelo moderno/colonial de desenvolvimento. Nesse intento, é possível observar influências e proximidades entre os dois constructos teóricos, sobretudo com relação ao foco nos países da América Latina, nas relações entre eles e deles com os países centrais.

A Cepal, voltada inicialmente às intervenções econômicas, amplia seu foco ao longo dos anos e, no presente, atua também nas áreas social e ambiental. A perspectiva decolonial, com foco mais centrado na análise histórico-estrutural, abarca os contextos sociais, culturais, políticos, ambientais e econômicos e propõe a transmodernidade e o bem viver como possibilidades para o giro decolonial.

Oriunda da ONU, a Cepal nasceu fora da academia, mais voltada para os Estados nacionais, governos, política e economia. A perspectiva decolonial, desde sua gênese, surge como resultado da atuação de intelectuais integrantes da academia, com clara ligação com a educação superior nas áreas de Humanidades e Ciências Sociais e com engajamento político e social com movimentos sociais.

Em que pese o fato de a formação epistemológica de seus pensadores ter sido composta das mais variadas influências, inclusive eurocêntricas, tanto a Cepal como os decoloniais empreendem esforços em busca de soluções endógenas, 
embora não isoladas do contexto global. Há similaridades nas origens e nas intenções epistemológicas e geográficas das duas perspectivas.

Ambos os pensamentos convergem na busca pela continuada reflexão histórica social e política da região, na crítica à dependência que insiste em manter a subordinação, na relação centro e periferia, que sempre privilegia os países centrais, e nos questionamentos acerca de uma economia euro-norte-centrada. Há, além da economia, divergências e tensionamentos sobre outros aspectos da vida, como a necessidade de industrialização como solução absoluta, a estrutura produtiva da região, a falta de coordenação entre setores econômicos dentro do mesmo país ou na região, o entendimento da complexidade do (pós-)desenvolvimento.

Esta proposta de aproximação entre as perspectivas apresentadas não tem a pretensão de esgotar a imensa variedade de possibilidades de tais relações, mas visa, em vez disso, dar destaque a alguns aspectos que dialogam na busca por alternativas - na América Latina - para uma racionalidade hegemônica imposta e perpetuada desde o colonialismo. Resta saber se a realidade atual, e como se chegou a ela, é suficientemente clara. Porque ela é base para um porvir/vir a ser cuja construção dependerá de quem serão seus atores e como cada um interpretará seu papel.

\section{Referências}

BALLESTRIN, L. América Latina e o giro decolonial. Revista Brasileira de Ciência Política, Brasília, DF, n. 11, p. 89-117, 2013.

BÁRCENA, A. 70 años de contribución al desarrollo sostenible de América Latina y el Caribe. In: CEPAL. Reflexiones sobre el desarrollo en América Latina y el Caribe: Conferencias magistrales 2016-2018. Santiago: LC/PUB.2018/14, [2018]. p. 57-67.

BIELSCHOWSKY, R. Evolución de las ideas de la Cepal. Revista de la Cepal, Santiago, n. esp., p. 21-45, 1998.

CAVALCANTE, L. R. M. T. Produção teórica em economia regional: uma proposta de sistematização. Revista Brasileira de Estudos Regionais e Urbanos, São Paulo, v. 2, n. 1, p. 9-32, 2008.

CEPAL. Comissão Econômica para a América Latina e o Caribe. Sobre a Cepal. 2019. Disponível em: https://www.cepal.org/pt-br/cepal-o. Acesso em: $1^{\circ}$ dez. 2019.

CLÍMACO, D. A. Prólogo. In: QUIJANO, A. Selección de Danilo Assis Clímaco. Cuestiones y horizontes: de la dependencia histórico-estructural a la colonialidad/descolonialidad del poder. Ciudad Autónoma de Buenos Aires: Clacso, 2014, p. 13-53.

COLISTETE, R. P. O desenvolvimentismo cepalino: problemas teóricos e influências no Brasil. Estudos Avançados, v. 15, n. 41, p. 21-34, 2001.

DIEGUES, A. C. S. Desenvolvimento sustentável ou sociedades sustentáveis: da crítica dos modelos aos novos paradigmas. São Paulo em Perspectiva, São Paulo, v. 6, n. 1-2, p. 2229, 1992. 
DUSSEL, E. 1492: o encobrimento do outro: a origem do mito da modernidade: Conferências de Frankfurt. Tradução: J. A. Clasen. Petrópolis: Vozes, 1993.

The invention of the Americas: eclipse of "the other" and the myth of modernity. Tradução: M. D. Barber. New York: Continuum, 1995.

ESCOBAR, A. Mundos y conocimientos de otro modo: El programa de investigación de modernidad/colonialidad latinoamericano. Tabula Rasa, Bogotá, n. 1, p. 51-86, 2003.

O lugar da natureza e a natureza do lugar: globalização ou pós-desenvolvimento? In: LANDER, E. (org.). A colonialidade do saber: eurocentrismo e ciências sociais. Perspectivas latino-americanas. Ciudad Autónoma de Buenos Aires: Clacso, 2005. p. 133168. (Coleccíon Sur).

La invención del Tercer Mundo: Construcción y deconstrucción del desarrollo. Caracas: Fundación Editorial el perro y la rana, 2007.

FANON, F. Os condenados da terra. Rio de Janeiro: Civilização Brasileira, 1968.

FREIRE, P. Pedagogia do oprimido. 42. ed. Rio de Janeiro: Paz e Terra, 2005.

FURTADO, C. Teoria e política do desenvolvimento econômico. São Paulo: Companhia Editora Nacional, 1977.

Globalização das estruturas econômicas e identidade nacional. Estudos Avançados, São Paulo, v. 6, n. 16, p. 55-64, 1992.

GRACIARENA, J. Poder y estilos de desarrollo. Una perspectiva heterodoxa. Revista de la Cepal, n. 1, p. 173-193, 1976.

GROSFOGUEL, R. Para descolonizar os estudos de economia política e os estudos pós-coloniais: transmodernidade, pensamento de fronteira e colonialidade global. Revista Crítica de Ciências Sociais, n. 80, p. 115-147, 2008.

Desenvolvimento, modernidade e teoria da dependência na América Latina. Revista de Estudos AntiUtilitaristas e PosColoniais, v. 3, n. 2, p. 26-55, 2013.

GUDYNAS, E. Buen vivir: germinando alternativas al desarrollo. América Latina en Movimiento, Quito, n. 462, p. 1-20, 2011.

LANDER, E. Ciências sociais: saberes coloniais e eurocêntricos. In: LANDER, E. (org.). A colonialidade do saber: eurocentrismo e ciências sociais. Perspectivas latino-americanas. Ciudad Autónoma de Buenos Aires: Clacso, 2005. p. 8-23. (Coleccíon Sur).

LITTLE, P. E. Etnodesenvolvimento local: autonomia cultural na era do neoliberalismo global. Tellus, Campo Grande, ano 2, n. 3, p. 33-52, 2002.

MIGNOLO, W. Desobediência epistêmica: a opção descolonial e o significado de identidade em política. Cadernos de Letras da UFF - Dossiê: Literatura, língua e identidade, n. 34, p. 287-324, 2008.

Desafios decoloniais hoje. Epistemologias do Sul, Foz do Iguaçu, n. 1, p. 12-32, 2017.

ONU. Organização das Nações Unidas. Cepal: Comissão Econômica para a América Latina e o Caribe. 2019. Disponível em: https://nacoesunidas.org/agencia/cepal/. Acesso em: 9 dez. 2019. 
PENNA, C. Paulo Freire no pensamento decolonial: um olhar pedagógico sobre a teoria pós-colonial latino-americana. Revista de Estudos \& Pesquisas sobre as Américas, v. 8, n. 2, p. 182-199, 2014.

PREBISCH, R. O desenvolvimento econômico da América Latina e alguns de seus problemas principais. In: CEPAL. Boletín Económico de América Latina, Santiago do Chile, v. VII, n. 1, 1962. Disponível em: https://repositorio.cepal.org/handle/11362/1611. Acesso em: 12 abr. 2020 .

Notas sobre el desarrollo del capitalismo periférico. Estudios Internacionales, ano 11, n. 43, p. 3-25, 1978.

Por uma dinâmica do desenvolvimento latino-americano. In: BIELSCHOWSKY, R. (org.). Cinquenta anos de pensamento na Cepal. Rio de Janeiro: Record, 2000. v. 1.

QUIJANO, A. A colonialidade do poder: eurocentrismo e América Latina. In: LANDER, E. (org.). A colonialidade do saber: eurocentrismo e ciências sociais. Perspectivas latino-americanas. Ciudad Autónoma de Buenos Aires: Clacso, 2005. p. 117-142.

Cuestiones y horizontes: de la dependencia histórico-estructural a la colonialidad/descolonialidad del poder. Selección de Danilo Assis Clímaco. Ciudad Autónoma de Buenos Aires: Clacso, 2014.

RADOMSKY, G. F. W. Desenvolvimento, pós-estruturalismo e pós-desenvolvimento: a crítica da modernidade e a emergência de "modernidades” alternativas. Revista Brasileira de Ciências Sociais, v. 26, n. 75, p. 149-162, 2011.

RIBEIRO, A. M. O pensamento crítico acerca da universidade na América Latina: de Darcy Ribeiro à "modernidade-colonialidade". Revista de Estudos \& Pesquisas sobre as Américas, v. 8, n. 2, p. 149-163, 2014.

RODRÍGUEZ, O. O pensamento da Cepal: síntese e crítica. Novos Estudos, São Paulo, n. 16, p. 8-28, dez. 1986.

O estruturalismo latino-americano. Tradução: Maria Alzira Brum Lemos. Rio de Janeiro: Civilização Brasileira, 2009.

STAVENHAGEN, R. Etnodesenvolvimento: uma dimensão ignorada no pensamento desenvolvimentista. Anuário Antropológico. Rio de Janeiro: Tempo Brasileiro, 1984.

TAVARES, M. C. Transformações do modelo de desenvolvimento na América Latina. In: MELO, H. P. (org.). Maria da Conceição Tavares: vida, ideias, teorias e políticas. São Paulo: Fundação Perseu Abramo, 2019a.

Estagnação ou crise? In: MELO, H. P. (org.). Maria da Conceição Tavares: vida, ideias, teorias e políticas. São Paulo: Fundação Perseu Abramo, 2019b.

WALLERSTEIN, I. Impensar las ciencias sociales: límites de los paradigmas decimonónicos. Ciudad de México: Siglo XXI Editores, 1998.

Capitalismo histórico e civilização capitalista. Rio de Janeiro: Contraponto, 2001.

WOLFE, M. Enfoques del desarrollo: ¿De quién y hacia qué? Revista de la Cepal, n. 1, p. 129$172,1976$. 


\section{Antônio Carlos Mazzetti}

Graduado em Letras pela Universidade Estadual de Mato Grosso (UEMS), mestre em Desenvolvimento Regional e doutorando no Programa de Pós-graduação em Desenvolvimento Regional da Universidade Tecnológica Federal do Paraná (UTFPR). Membro do Grupo de Estudos sobre Universidade (GEU/UTFPR). Servidor técnico administrativo da UTFPR.

Email: antoniomazzetti@yahoo.com.br

ORCID: 0000-0002-6402-2159

Contribuição de autoria: conceituação; análise formal; investigação/pesquisa; metodologia; visualização; escrita - primeira redação; escrita - revisão e edição.

\section{Josiane Carine Wedig}

Licenciada e bacharela em Ciências Sociais pela Universidade Federal de Pelotas (UFPel), mestre em Desenvolvimento Rural pela Universidade Federal do Rio Grande do Sul (UFRGS) e doutora em Ciências Sociais, na área de Desenvolvimento, Agricultura e Sociedade, pela Universidade Federal Rural do Rio de Janeiro (UFRRJ). Professora do Departamento de Ciências Humanas e da Pós-graduação em Desenvolvimento Regional da Universidade Tecnológica Federal do Paraná (UTFPR). Líder do grupo de pesquisa Gênero, Juventude e Cartografias da Diferença.

Email: josiwedig@gmail.com

ORCID: 0000-0003-4569-6956

Contribuição de autoria: conceituação; análise formal; escrita - primeira redação; escrita - revisão e edição. 


\section{Miguel Angelo Perondi}

Graduado em Agronomia pela Universidade Federal do Paraná (UFPR), mestre em Administração pela Universidade Federal de Lavras (UFLA) e doutor em Desenvolvimento Rural pela Universidade Federal do Rio Grande do Sul (UFRGS). Professor do Departamento de Agronomia e da Pós-graduação em Desenvolvimento Regional da Universidade Tecnológica Federal do Paraná (UTFPR).

Email: miguelangeloperondi@gmail.com

ORCID: 0000-0003-4382-4571

Contribuição de autoria: conceituação; análise formal; escrita - primeira redação.

\section{Marlize Rubin-Oliveira}

Licenciada em Educação Física pela Universidade Federal de Santa Maria (UFSM) e mestre em Educação pela Universidade Federal de Pelotas (UFPel). Professora associada do Departamento de Ciências Humanas e do Programa de Pós-graduação em Desenvolvimento Regional Sustentável da Universidade Tecnológica Federal do Paraná (UTFPR). Líder do grupo de estudos sobre Universidade (GEU/UTFPR). Doutora em Educação pela Universidade Federal do Rio Grande do Sul (UFRGS). Professora visitante no Department of Lifelong Education, Administration, and Policy da University of Georgia (2017-2018).

Email: rubin@utfpr.edu.br

ORCID: 0000-0003-3234-7562

Contribuição de autoria: conceituação; supervisão/orientação; metodologia; validação; visualização; escrita - revisão e edição.

Submissão: 13 de outubro de 2020.

Aprovação: 18 de março de 2021.

Como citar: MAZZETTI, A. C.; WEDIG, J. C.; PERONDI, M. A.; RUBIN-OLIVEIRA, M. América Latina em perspectiva: o pensamento cepalino e decolonial. Revista brasileira de estudos urbanos e regionais. v. 23, E202111, 2021. DOI 10.22296/2317-1529.rbeur.202111

Artigo licenciado sob Licença Creative Commons CC BY 4.0.

https://creativecommons.org/licenses/by/4.o/deed.pt_BR 